\title{
Proposta de melhoria das propriedades familiares a partir da introdução de cultivos florestais
}

\author{
Proposal for improvement of the familiar properties through introduction \\ of forest plantations
}

\author{
Milton Satoshi Matsushita ${ }^{[a]}$, Vitor Afonso Hoeflich ${ }^{[b]}$, Carlos Augusto Petersen Parchen ${ }^{[c]}$, \\ Ivone Satsuki Namikawa ${ }^{[\mathrm{d}]}$
}

[a] Engenheiro agrônomo, Mestre, Doutorando na área de Economia do curso de Engenharia Florestal pela Universidade Federal do Paraná (UFPR), professor adjunto da Faculdade de Campina Grande do Sul (Facsul), professor adjunto das Faculdades Integradas Espírita (FIES), Curitiba, PR - Brasil, e-mail: matsushita@emater.pr.gov.br

[b] Engenheiro agrônomo, Doutor, Universidade Federal do Paraná (UFPR), Curitiba, PR - Brasil, e-mail: vitor.ufpr@gmail.com

[c] Engenheiro agrônomo, Doutor, Ciências Florestais pela Universidade Federal do Paraná (UFPR), professor adjunto da Pontifícia Universidade Católica do Paraná (PUCPR), Curitiba, PR - Brasil, e-mail: carlosparchen@emater.pr.gov.br

[d] Engenheira florestal, coordenadora de Pesquisa \& Desenvolvimento, Qualidade e Ambiência Florestal da Klabin, Doutoranda em Economia Florestal pela Universidade Federal do Paraná (UFPR), Telêmaco Borba, PR - Brasil, e-mail: namikawa@klabin.com.br

\section{Resumo}

A forte competição gerada pela estabilização da economia nacional e pela globalização dos mercados atingiu a agricultura (principalmente a produção familiar), gerou concentração de terras e renda e acelerou o processo de degradação dos recursos naturais. Em razão da situação apresentada, projetou-se a melhoria econômica nas propriedades familiares, por meio da introdução do cultivo florestal em áreas subutilizadas ou exploradas com lavouras ou pastagens com baixos rendimentos, adequando as atividades à capacidade de uso das terras, melhorando o índice de eficiência, reduzindo o impacto ambiental e garantindo a sustentabilidade do sistema de produção, elevando as condições sociais de seus familiares. A proposta foi analisada com apoio de planilha eletrônica Microsoft ${ }^{\circledR}$ Excel 2002, aplicando as funções financeiras Valor Presente Líquido (VPL), Taxa Interna de Retorno (TIR) e Análise de Sensibilidade, organizando os resultados em classes de VPL e TIR das atividades individuais e da situação proposta.

Palavras-chave: Propriedades familiares. Sistema de produção. Cultivos florestais. Análise de investimento. 


\begin{abstract}
The strong competition generated by the stabilization of the national economy and by the globalization of the markets reached agriculture (mainly the familiar production), generated land and income concentration and speeded up the process of natural resources degradation. In reason of the presented situation, it was projected economic improvement in the familiar properties through the introduction of the forest culture in areas underutilized or explored with farmings or pastures with low incomes, adjusting the activities to its capacity land's use, improving its index of efficiency, reducing the ambient impact and guaranteeing the sustainable of the production system, raising the social conditions of family members. The offer was analyzed with support of electronic spreadsheet Microsoft ${ }^{\circledR}$ Excel 2002, applying financials functions Net Present Value (NPV), Internal Rate of Return (IRR) and Analysis of Sensibility, organizing the results in grades of NPV and IRR of individuals activities and of proposal situation.
\end{abstract}

Keywords: Familiar properties. Production system. Forest plantation. Investment analysis.

\title{
Introdução
}

Segundo o Instituto Brasileiro de Geografia e estatística (IBGE), censo agropecuário 1995/96, os agricultores familiares paranaenses, em número de 321.000, representam $86,9 \%$ dos estabelecimentos agropecuários do Estado, ocupam 41\% da área total e respondem por 48\% do valor bruto da produção agrícola estadual (IBGE, 1996).

Apesar de sua importância econômica e social, esse segmento não recebe toda a atenção devida por parte dos governos federal e estadual, tornando-se excluído do processo de desenvolvimento. Os agricultores transformam em marginalizados da sociedade e passam a migrar para as periferias das grandes cidades do Estado.

As recentes pesquisas realizadas pelo Instituto Paranaense de Desenvolvimento Econômico e Social apresentam a enorme diversidade interna na agricultura familiar e demonstram a situação de pobreza como uma característica marcante (IPARDES, 2003).

A agricultura paranaense e brasileira incorporou as tecnologias mais atuais no processo de transformação da sua base técnica e elevou seus rendimentos aos níveis das nações mais desenvolvidas, mas paradoxalmente mantém uma diversidade estrutural e social com forte tendência dos agricultores familiares continuarem pobres e saírem em busca de melhores alternativas no meio urbano. Esta situação faz com que o Estado busque alternativas que permitam a sobrevivência destes agricultores familiares em seu meio original.

Os indicadores organizados pelo Instituto Paranaense de Assistência Técnica e Extensão Rural (Emater-PR), para elaboração do Sistema de Informações para o Planejamento de 2006, demonstram que a agropecuária paranaense tem uma importância significativa na economia do Estado e que por muitas décadas as explorações foram cultivadas por meio dos sistemas de manejo convencional, produzindo altos rendimentos com as culturas e pastagens (EMATER-PR, 2006).

Com base no Valor Bruto da Produção de 2004, calculado pela Secretaria de Estado da Agricultura e Abastecimento (SEAB, 2006b), observa-se que o setor florestal possui vários ramos de atividades e representa uma importante fonte de receitas $(8,75 \%$ do VPB estadual) e ocupação de mão de obra, permitindo produção tanto para o mercado interno quanto para o externo. O crescimento significativo do setor ocorreu graças aos incentivos fiscais, principalmente nas décadas de 70 e 80 , quando houve intenso plantio de florestas homogêneas, cujo objetivo foi promover o uso da madeira proveniente de reflorestamento, para reduzir o desmatamento.

A gestão racional dos recursos florestais depende de conhecimentos econômicos, ecológicos, sociais e políticos, para que as florestas possam ter um manejo sustentável, envolvendo as atividades relacionadas com a implantação, crescimento, manutenção, colheita e comercialização da produção, cujo retorno econômico ocorre em longo prazo, a partir do corte do seu fator de produção (floresta), conforme descrito por Silva et al. (2002). 
Assim, a administração e a economia florestal podem colaborar no diagnóstico, planejamento, acompanhamento, controle e segurança na tomada de decisão mais lucrativa ou que resultem em benefícios indiretos, garantindo o sucesso da atividade florestal na propriedade familiar, na microbacia, no município, e com reflexos positivos para a sociedade.

O presente trabalho teve como objetivo projetar a melhoria econômica nas propriedades familiares de uma microbacia a partir da introdução do cultivo florestal em áreas subutilizadas ou com baixos rendimentos, adequando as atividades à sua capacidade de uso das terras.

\section{Materiais e métodos}

\section{Área de estudo}

O estudo de caso foi realizado em uma bacia hidrográfica localizada na comunidade Santa Bárbara, no município de Palmeira, PR.

O município de Palmeira está localizado na região centro-sul do Estado, entre a latitude $25^{\circ} 25^{\prime} 46^{\prime \prime}$ Sul e longitude $50^{\circ} 00^{\prime} 23^{\prime \prime}$ Oeste, a uma distância de $80 \mathrm{~km}$ da capital, e possui uma área territorial de 1.457,263 $\mathrm{km}^{2}$. O município possui uma grande concentração de agricultores familiares, 88,8\% de um total de 1.787 agricultores, com exploração de culturas anuais como o milho, soja, trigo e pastagem.

\section{Dados}

O estudo foi realizado com a utilização de diversas fontes de dados primários e secundários para caracterização física e socioeconômica das atividades e da bacia hidrográfica e do município de Palmeira:

a) série histórica de dados relativos à produção, produtividade (SEAB, 2006c), preços e custos de soja, milho e leite (SEAB, 2006a) obtidos do Departamento de Economia Rural da Secretaria de Agricultura e Abastecimento do Paraná (SEAB/DERAL), durante o período de quatro anos (2002/03 a 2005/06);

b) série histórica de dados relativos à produção, produtividade, preços e custos de eucalipto obtidos da Klabin S.A. - Klabin Florestal Paraná, durante o período de quatro anos (2002/03 a 2005/06);

c) materiais georreferenciados gerados pelo Laboratório de Informações Geográficas da Fundação ABC:

- ortofotos cartas geradas a partir de fotografias aéreas de 2004;

- cartas topográficas elaboradas a partir das Ortofotos cartas de 2004;

- mapas hidrográficos gerados a partir das Ortofotos cartas de 2004.

d) mapa de solos em formato digital, em coordenadas planas, elaborado pelo Centro Nacional de Pesquisa de Solos da Empresa Brasileira de Pesquisa Agropecuária (1999).

O método utilizou o Sistema de Informações Geográficas para conhecer as potencialidades e limitações dos recursos naturais, humanos, sociais e econômicos da bacia hidrográfica do município de Palmeira, a fim de se propor alternativas sociais, ambientais e economicamente sustentáveis.

\section{Métodos de análise de investimento}

Os métodos determinísticos de análise de investimentos, conforme descrito por Casarotto e Kopittke (2000), Dossa (2000) e Dossa et al. (2000), permitem analisar investimentos de longo prazo, em que os dados de entrada são perfeitamente conhecidos e definidos, possibilitando obter o máximo ganho em determinado horizonte de análise a um custo de recuperação do capital (taxa). 


\section{a) Método do Valor Presente Líquido (VPL)}

Este método estima o valor de hoje de um fluxo de caixa, usando para isso uma taxa básica de atratividade do capital. Calcula o valor presente de todos os termos do fluxo de caixa, com base na taxa de mínima atratividade (TMA), mais o investimento inicial.

O VPL é compreendido como a quantia equivalente, na data zero, de um fluxo financeiro, descontando-se a taxa de juros determinada pelo mercado. A atividade é desejável se o VPL for superior ao valor do investimento, pagando-se a taxa de juros determinada para o uso alternativo daquele dinheiro que, neste trabalho, é o da caderneta de poupança ( $6 \%$ ao ano). O modelo geral que permite trazer a uma taxa de desconto os valores de cada período de tempo para o valor de hoje, dos investimentos, dos custos, das receitas, pode ser apresentada por meio da fórmula a seguir:

$$
\mathrm{VPL}=\sum_{\mathrm{n}=0}^{\mathrm{t}} \frac{\mathrm{Rn}-\mathrm{Cn}}{(1+\mathrm{i})^{\mathrm{n}}}=0
$$

Onde:

$\mathrm{Rn}=$ receitas;

$\mathrm{Cn}=$ custos operacionais.

Neste trabalho o VPL foi estimado na planilha Microsoft ${ }^{\circledR}$ Excel 2002, usando-se a seguinte sintaxe:

= VPL (taxa de desconto i; Fluxo), onde = VPL (6\%; Saldo do fluxo de caixa).

\section{b) Método da Taxa Interna de Retorno (TIR)}

A TIR é uma taxa de desconto em que o VPL dos benefícios é igual ao VPL dos custos econômicos. Ela pode ser considerada como a taxa de juros que anula o VPL de um fluxo de caixa. A TIR representa a eficiência marginal do capital e corresponde, em última análise, à taxa de lucratividade esperada dos projetos de investimento. Esta taxa é considerada há muitos anos como o indicador fundamental para análise de viabilidade e seleção de propostas de investimento em novos projetos.

A regra de decisão indica que somente se fará investimentos se a TIR for maior que a taxa de juros no mercado financeiro; neste caso, o da caderneta de poupança ( $6 \%$ ao ano). A escolha de um investimento deve necessariamente recair sobre aquele que tiver a maior TIR. Quanto maior for a TIR, mais desejável é o investimento.

O modelo geral retorna à taxa de juros recebida para um investimento que consiste em pagamentos (valores negativos) e receitas (valores positivos) que ocorrem em períodos regulares, pode ser apresentado por meio da fórmula a seguir:

$$
\mathrm{TIR}=\sum_{\mathrm{n}=0}^{\mathrm{t}} \frac{\text { Fluxo líquido }}{(1+\mathrm{i})^{\mathrm{n}}}=0
$$

Neste trabalho a TIR foi estimada na planilha Microsoft ${ }^{\circledR}$ Excel 2002, usando-se a seguinte sintaxe: $=$ TIR (Fluxo; estimativa i), onde = TIR (Fluxo líquido; 6\%).

\section{c) Análise de sensibilidade}

A análise de sensibilidade estuda o efeito que a variação de um dado de entrada pode ocasionar no resultado. Ela pode ser calculada em função de uma variável que reflete aumentando ou diminuindo as receitas ou as despesas. 
Conforme Dossa et al. (2000), a técnica de análise de sensibilidade é muito utilizada atualmente para estudar as variações possíveis na renda do produtor. Esta variação se dá em função dos riscos e das incertezas a que estão submetidas a produção, a armazenagem e a comercialização rural. A variação da renda anual do produtor é uma consequência da variação dos preços e da produtividade, enquanto a do custo de produção depende de fatores tecnológicos e ambientais.

\section{Instrumento de análise}

A planilha eletrônica VPL-TIR-Sensibilidade, desenvolvida em Microsoft ${ }^{\circledR}$ Excel 2002 por Matsushita e Parchen (2006), foi utilizada como ferramenta de apoio para a avaliação do projeto, aplicando as funções financeiras existentes VPL e TIR, elaborando fórmulas de cálculos e Análise de Investimento por meio de cálculos básicos e combinação de dados.

A análise da sensibilidade foi realizada a partir da produtividade e do preço médio dos últimos quatro anos, estabelecendo-se como limites inferior e superior a variação em $20 \%$ a partir desta média, usando como parâmetro o trabalho de Dossa et al. (2000). Estes autores, após profunda observação sobre o comportamento de várias culturas anuais e florestais, consideraram uma variação de $20 \%$ em torno da média histórica de preços, e de $20 \%$ em torno da média histórica de rendimentos das atividades. Aplicou-se a função aleatória da Microsoft ${ }^{\circledR}$ Excel 2002, gerando cem valores de produtividade e cem valores de preço, dentro dos limites preestabelecidos para cada atividade. Mantendo-se o custo inalterado, foi calculado o Valor Presente Líquido Anual e a Taxa Interna de Retorno. Estratificaram-se os resultados em quatro classes de VPL (inferior a 0,00; entre 0,00 e 3.000,00; entre 3.000,01 e 6.000,00; e acima de 6.000,00) e quatro classes de TIR (inferior a 0,0\%; entre $0,0 \%$ e $6,0 \%$, entre $6,1 \%$ e $12,0 \%$ e acima de $12,0 \%$ ).

O VPL e TIR foram calculados para um período de tempo de 21 anos para todas as atividades, considerando que o sistema de produção utilizado para cultivo de eucalipto possui este horizonte, baseado na tecnologia citada pela Klabin (2009), com três cortes: 8 anos (primeiro desbaste - madeira para energia), 14 anos (segundo desbaste - madeira para serrados) e 21 anos (corte final - madeira para serrados).

\section{Resultados e discussão}

Os resultados foram obtidos a partir de dados médios levantados durante o período de quatro anos (2002/03 a 2005/06), cujos preços, receitas e custos foram atualizados pela variação mensal do Índice Geral de Preços - Disponibilidade Interna (IGP-DI) da Fundação Getúlio Vargas, para o mês de outubro de 2009. A partir destes dados, foram geradas cem variações aleatórias de produtividade e do preço dos produtos, responsáveis pela variação da renda bruta da atividade utilizada para calcular e classificar o VPL e a TIR.

A Tabela 1 apresenta a produtividade, preço, receita, custo, VPL e TIR das atividades de milho, soja, leite e eucalipto.

As 39 propriedades familiares localizadas na área de estudo possuem em média área de 12,60 ha e exploram a cultura de milho, soja e pecuária de leite como atividades geradoras de renda. O uso do solo na situação atual foi obtido com uso de ortofotocartas, confirmadas com visita a campo.

O cultivo florestal com eucalipto $(15,2 \%)$ e a pecuária de leite $(13,8 \%)$ apresentam taxa interna de retorno superior à situação proposta (12,2\%) com o conjunto de atividades, porém os agricultores familiares sempre buscam maior segurança, minimizando seus riscos por meio da diversificação e manutenção das atividades tradicionais.

A Tabela 2 indica a situação atual e a situação proposta para melhoria das condições econômicas, social e ambiental das propriedades, a partir do incremento de cultivo florestal (eucalipto).

A situação proposta procura adequar o uso do solo e a situação ambiental da propriedade, com base na aptidão dos solos e no relevo do terreno, mantendo a área mínima necessária de preservação permanente. As áreas disponíveis com capoeira foram readequadas, sendo transformadas em áreas de cultivo florestal e preservação permanente, com redução de 0,5 ha de pastagem para utilizar com cultivo florestal. 
Tabela 1 - Dados médios de quatro anos (2002/03 a 2005/06) e limites (mais e menos 20\% da média)

\begin{tabular}{|c|c|c|c|c|c|c|}
\hline Limites & Produtividade $^{1}$ & Preço & Receita & Custo & VPL & TIR \\
\hline \multicolumn{7}{|c|}{ Milho } \\
\hline Média quatro anos & 89,8 & 19,51 & $1.751,98$ & $1.652,07$ & 10,35 & $6,1 \%$ \\
\hline Média - 20\% & 71,8 & 15,61 & $1.120,80$ & $1.652,07$ & $(7.412,78)$ & $-10,0 \%$ \\
\hline Média + 20\% & 107,8 & 23,41 & $2.523,60$ & $1.652,07$ & $9.092,22$ & $52,8 \%$ \\
\hline \multicolumn{7}{|c|}{ Soja } \\
\hline Média quatro anos & 42,9 & 42,08 & $1.805,23$ & $1.701,51$ & 10,35 & $6,1 \%$ \\
\hline$M-20 \%$ & 34,3 & 33,66 & $1.154,54$ & $1.701,51$ & $(7.636,30)$ & $-10,0 \%$ \\
\hline$M+20 \%$ & 51,5 & 50,50 & $2.600,75$ & $1.701,51$ & $9.374,56$ & $52,8 \%$ \\
\hline \multicolumn{7}{|c|}{ Leite } \\
\hline Média quatro anos & $1.615,3$ & 0,56 & 904,57 & 795,23 & 732,90 & $13,8 \%$ \\
\hline$M-20 \%$ & $1.292,2$ & 0,45 & 581,49 & 795,23 & $(3.078,66)$ & $-10,0 \%$ \\
\hline$M+20 \%$ & $1.938,4$ & 0,67 & $1.298,73$ & 795,23 & $5.367,95$ & $63,4 \%$ \\
\hline \multicolumn{7}{|c|}{ Eucalipto } \\
\hline Média quatro anos & 671,0 & 45,00 & $30.195,00$ & $8.628,00$ & $6.172,18$ & $15,2 \%$ \\
\hline$M-20 \%$ & 536,8 & 36,00 & $19.324,80$ & $8.628,00$ & 945,10 & $7,8 \%$ \\
\hline$M+20 \%$ & 805,2 & 54,00 & $43.480,80$ & $8.628,00$ & $12.561,60$ & $21,6 \%$ \\
\hline \multicolumn{7}{|c|}{ Situação atual } \\
\hline Média quatro anos & & & $10.175,85$ & $9.362,67$ & $2.955,37$ & $8,7 \%$ \\
\hline$M-20 \%$ & & & $6.520,27$ & $9.362,67$ & $(40.054,09)$ & $-10,0 \%$ \\
\hline$M+20 \%$ & & & $14.641,69$ & $9.362,67$ & $55.493,74$ & $56,4 \%$ \\
\hline \multicolumn{7}{|c|}{ Situação proposta } \\
\hline Média quatro anos & & & $70.113,56$ & $26.221,06$ & $14.946,14$ & $12,2 \%$ \\
\hline$M-20 \%$ & & & $44.879,13$ & $26.221,06$ & $(36.612,45)$ & $-10,0 \%$ \\
\hline$M+20 \%$ & & & $100.953,93$ & $26.221,06$ & $77.934,28$ & $36,2 \%$ \\
\hline
\end{tabular}

As medidas geradoras de renda na situação proposta mantêm todas as atividades produtivas atuais, agregando uma área de 2,0 ha de cultivo florestal com eucalipto. A Tabela 3 apresenta os indicadores econômicos da situação atual e a situação proposta com o cultivo de eucalipto.

${ }_{1}^{1}$ Produtividade: milho e soja (sacas de $60 \mathrm{~kg} / \mathrm{ha}$ ); leite (litros/animal/ano) e eucalipto (metros stereo/ha). 
Tabela 2 - Uso do solo na situação atual e proposta

\begin{tabular}{lcccccc}
\hline \multirow{2}{*}{ Uso do solo } & \multicolumn{2}{c}{ Situação atual } & & \multicolumn{2}{c}{ Situação proposta } \\
\cline { 2 - 3 } \cline { 6 - 7 } & Área (ha) & $\mathbf{( \% )}$ & & Área (ha) & $\mathbf{( \% )}$ \\
\hline Milho & 1,27 & 10,1 & & 1,27 & 10,1 \\
Soja & 2,4 & 19,0 & & 2,4 & 19,0 \\
Pastagem & 4,0 & 31,7 & & 3,5 & 27,8 \\
Capoeira & 3,47 & 27,5 & & 0,0 & 0,0 \\
APP (Área de Preservação Permanente) & 1,22 & 9,7 & & 3,13 & 24,8 \\
Cultivo florestal & 0,0 & 0,0 & & 2,0 & 15,9 \\
Outras & 0,24 & 1,9 & & 0,3 & 2,4 \\
\hline Total & $\mathbf{1 2 , 6}$ & $\mathbf{1 0 0 , 0}$ & & $\mathbf{1 2 , 6}$ & $\mathbf{1 0 0 , 0}$ \\
\hline
\end{tabular}

Tabela 3 - Indicadores econômicos da situação atual e proposta

\begin{tabular}{lcc}
\hline \multicolumn{1}{c}{ Indicadores } & Situação atual & $\begin{array}{c}\text { Situação proposta } \\
\text { com eucalipto }\end{array}$ \\
\hline Taxa de desconto & $6,0 \%$ & $6,0 \%$ \\
Número de anos do projeto & 21 anos & 21 anos \\
VPL & $\mathrm{R} \$ 2.955,37$ & $\mathrm{R} \$ 14.946,14$ \\
TIR & $8,7 \%$ & $12,2 \%$ \\
\hline
\end{tabular}

A análise da situação atual indicou uma taxa interna de retorno de 8,7\%, superior à taxa de mínima atratividade, considerando o rendimento da caderneta de poupança ( $6 \%$ ao ano); portanto, os produtores conseguem manter-se na propriedade com as atividades atuais, porém sem muitas perspectivas de melhorias. Na situação proposta, a taxa interna de retorno foi de 12,2\%, superior à taxa de mínima atratividade, o que indica que esta proposta também é viável, e superior à situação atual.

Realizando a análise com base no VPL, verificamos que a situação atual apresenta um VPL de $\mathrm{R} \$ 2.955,37$ contra um VPL de R \$14.946,14 na situação proposta com o incremento de eucalipto, levando-se em consideração os dados médios obtidos no Estado do Paraná.

As Tabelas 4 e 5 apresentam os resultados do Valor Presente Líquido Anual e da Taxa Interna de Retorno obtidos com cem variações aleatórias da produtividade e do preço dos produtos, responsáveis pela variação da renda bruta da atividade, enquanto os custos de produção foram mantidas inalteradas pela média das últimas quatro safras.

Os resultados de todas as simulações indicam o eucalipto como única atividade a apresentar um VPL anual positivo, enquanto a situação proposta com a combinação de atividades apresenta $90 \%$ das situações com VPL anual positivo. Ainda podemos observar que as atividades individuais apresentam o VPL negativo em várias situações - soja (56\%), milho (54\%) e leite (35\%) -, enquanto a situação atual apresenta $37 \%$ das situações com VPL negativo. 
Tabela 4 - Análise de Sensibilidade - classes de VPL com variação da produtividade e preço dos produtos

\begin{tabular}{|c|c|c|c|c|c|c|}
\hline VPL (R\$) & Milho & Soja & Leite & Eucalipto & $\begin{array}{c}\text { Situação } \\
\text { atual }\end{array}$ & $\begin{array}{l}\text { Situação } \\
\text { proposta }\end{array}$ \\
\hline Abaixo de 0,00 & 53 & 56 & 35 & 0 & 37 & 10 \\
\hline 0,00 a $3.000,00$ & 26 & 25 & 50 & 4 & 12 & 5 \\
\hline $3.000,01$ a $6.000,00$ & 15 & 12 & 15 & 37 & 12 & 7 \\
\hline Acima de $6.000,00$ & 6 & 7 & 0 & 59 & 39 & 78 \\
\hline Total & 100 & 100 & 100 & 100 & 100 & 100 \\
\hline
\end{tabular}

Tabela 5 - Análise de Sensibilidade - classes de TIR com variação da produtividade e preço dos produtos

\begin{tabular}{lcccccc}
\hline TIR (\%) & Milho & Soja & Leite & Eucalipto & $\begin{array}{c}\text { Situação } \\
\text { atual }\end{array}$ & $\begin{array}{c}\text { Situação } \\
\text { proposta }\end{array}$ \\
\hline Abaixo de $\mathbf{0 , 0} \%$ & 38 & 38 & 22 & 0 & 21 & 0 \\
$\mathbf{0 , 0}$ a $\mathbf{6 , 0} \%$ & 15 & 18 & 13 & 0 & 16 & 10 \\
$\mathbf{6 , 1} \mathbf{~ a ~} \mathbf{1 2 , 0} \%$ & 8 & 12 & 12 & 5 & 27 & 34 \\
Acima de $\mathbf{1 2 , 0 \%}$ & 39 & 32 & 53 & 95 & 36 & 56 \\
\hline Total & 100 & 100 & 100 & 100 & 100 & 100 \\
\hline
\end{tabular}

A análise pela Taxa Interna de Retorno apresenta o eucalipto como única atividade com taxa superior a $6 \%$ em todas as simulações, enquanto a situação proposta com a combinação de atividades apresenta $90 \%$ das ocorrências com TIR superior a $6 \%$ e 100\% das ocorrências com TIR positiva.

As atividades individuais apresentam grande percentual de ocorrências com a TIR inferior à taxa de mínima atratividade desejada: a soja com $56 \%$, o milho com $53 \%$ e leite com $35 \%$. A ocorrência de taxas inferiores à de mínima atratividade desejada também foi observada em 37\% da situação atual e em 10\% das propriedades com a combinação de atividades da situação proposta.

\section{Conclusões}

A partir dos estudos realizados, podemos concluir que a situação proposta com a combinação de atividades permite obter melhor aproveitamento dos recursos naturais e da mão de obra, e com alta eficiência econômica, além de permitir que os produtores continuem trabalhando com segurança, pela preservação das atividades já conhecidas.

O incremento de eucalipto ao sistema de produção atual não causará competição com as atividades atualmente exploradas, além de permitir um incremento médio significativo na renda da propriedade ao longo de 21 anos. 
A estrutura agrária do município apresenta $80 \%$ das propriedades abaixo de 50 ha, sendo a maioria delas propriedades familiares, e representa grande potencial para ingresso na atividade, contribuindo para criação de empregos no cultivo florestal, no transporte e nas indústrias, permitindo injeção de recursos e aumento de arrecadação de impostos no município.

A criação de um Plano Florestal de âmbito estadual, com a parceria e participação de instituições públicas (secretarias estaduais, universidades e escolas técnicas, institutos de pesquisas e extensão rural), instituições privadas (cooperativas, associações de produtores, indústrias madeireiras, fábrica de móveis) e outros setores da sociedade, com atuação direta ou indireta nas atividades ligadas ao setor florestal, fará com que os agricultores familiares tenham na atividade florestal uma alternativa de melhoria econômica, ambiental e social:

- financiamentos florestais com maior período de carência aos agricultores familiares e incentivos fiscais para as empresas que criarem mecanismos que permitam o cultivo florestal com uso de tecnologias, ocupando a mão de obra com a profissionalização das atividades, mantendo em parceria o agricultor e sua família no meio rural, adotando práticas de preservação do meio ambiente;

- remuneração aos produtores que aderirem ao plano, antecipando anualmente uma parcela das rendas para manutenção da atividade e da estrutura produtiva do cultivo florestal;

- aplicação de uma legislação mais clara e de fácil compreensão pelos agricultores familiares, que facilite e agilize o processo de obtenção de licenças para exploração, a fim de eliminar o receio dos produtores de implantar atividades de longo prazo, sem a certeza de poder explorar a madeira no futuro.

Os indicadores obtidos neste trabalho apresentam uma melhoria econômica nas propriedades familiares a partir da introdução do cultivo florestal, com menor risco e maior retorno econômico. Com a integração e conjugação de esforços, é possível criar um plano que possa viabilizar grande quantidade de produtores familiares.

\section{Referências}

CASAROTTO FILHO, N.; KOPITTKE, B. H. Análise de investimentos. 9. ed. São Paulo: Atlas, 2000.

DOSSA, D. A decisão econômica num sistema agroflorestal. Colombo: Embrapa Floresta, 2000. 24 p. (Embrapa Florestas. Circular Técnica, 39).

DOSSA, D. et al. Aplicativo com análise de rentabilidade para sistemas de produção de florestas cultivadas e de grãos. Colombo: Embrapa Florestas, 2000. (Embrapa Florestas. Documentos, 39).

INSTITUTO BRASILEIRO DE GEOGRAFIA E ESTATÍSTICA - IBGE. Censo Agropecuário 1995-1996 Paraná. Rio de Janeiro, IBGE, 1996.

INSTITUTO PARANAENSE DE ASSISTÊNCIA TÉCNICA E EXTENSÃO RURAL - EMATER-PR. Sistema de informações para planejamento da Emater-PR. Curitiba: Emater-PR Publicação Interna, 2006.

INSTITUTO PARANAENSE DE DESENVOLVIMENTO ECONÔMICO E SOCIAL - IPARDES. Paraná: Diagnóstico social e econômico. Curitiba: Ipardes, 2003.

KLABIN FLORESTAL PARANÁ. Cálculo de custo de plantio de eucalipto. Telêmaco Borba, PR: Klabin Publicação interna, 2009.

MATSUSHITA, M. S.; PARCHEN, C. A. P. Planilha VPL-TIR-Sensibilidade. Software desenvolvido em MS-Excel. Curitiba: Instituto Emater, 2006.

SECRETARIA DO ESTADO DA AGRICULTURA E DO ABASTECIMENTO - SEAB/DERAL. Estimativa do custo de produção no Paraná. Curitiba: SEAB/DERAL, 2006a.

Rev. Acad., Ciênc. Agrár. Ambient., Curitiba, v. 8, n. 2, p. 251-260, abr./jun. 2010 
Preços médios nominais recebidos pelos produtores no Paraná. Curitiba: SEAB/DERAL, 2006b.

Produtividade média obtida pelos produtores no Paraná. Curitiba: SEAB/DERAL, 2006c.

SILVA, M. L.; JACOVINE, L. A. G.; VALVERDE, S. R. Economia florestal. Viçosa, MG: Ed. da UFV, 2002.

Recebido: 22/03/2010

Received: 03/22/2010

Aprovado: $26 / 04 / 2010$

Approved: 04/26/2010 